\title{
ERRATUM
}

Emma Peré-Trepat $\cdot$ Mira Petrovic $\cdot$ Damià Barceló

Romà Tauler

\section{Application of chemometric methods to the investigation of main microcontaminant sources of endocrine disruptors in coastal and harbour waters and sediments}

Published online: 1 April 2004

(C) Springer-Verlag 2004

\section{Anal Bioanal Chem (2004) 378:642-654}

In our recent paper entitled 'Application of chemometric methods to the investigation of main microcontaminant sources of endocrine disruptors in coastal and harbor waters and sediments' published in a recent issue of this journal (Analytical and Bioanalytical Chemistry 2004, 378:642-654) we have used the term 'endocrine disruptors' incorrectly and we apologize for that. The disruptor character of the analyzed compounds has been only shown for three (nonylphenol, 4-octylphenol and nonylphenolmono and diethoxylates) of the seven type of studied chemical compounds. Linear alkylbenzenesulfonates, alcohol ethoxylates, polyethyleneglycol and coconut diethanolamide organic compounds have not been shown to have estrogenic activity (E. Routledge \& J.P. Sumpter, "Estrogenic activity of surfactants and some of their degradation products assessed using a recombinant yeast screen," Environmental Toxicology and Chemistry 15:241-8, 1996).

The online version of the original article can be found at http://dx.doi.org/10.1007/s00216-003-2322-2

E. Peré-Trepat $\cdot$ R. Tauler $(\bowtie)$

Department of Analytical Chemistry, University of Barcelona, Diagonal 647, 08028 Barcelona, Spain

e-mail: roma@apolo.qui.ub.es

M. Petrovic · D. Barceló

Department of Environmental Chemistry, IIQAB-CSIC,

Jordi Girona 18-26, 08034 Barcelona, Spain 